\title{
Perceived stress and musculoskeletal pain are prevalent and significantly associated in adolescents: an epidemiological cross- sectional study
}

Berit Østerås ${ }^{1,2^{*}}$, Hermundur Sigmundsson $^{2}$ and Monika Haga ${ }^{1}$

\begin{abstract}
Background: Long-term musculoskeletal pain and negative stress are health risks with adverse long-term health effects, and these health risks seem to increase among young people. The mechanisms behind this are unclear. There is a need for a better understanding of perceived stress and musculoskeletal pain among adolescents, in order to improve health promotion and treatment approaches in this group.

Methods: Objectives were to evaluate the current prevalence of perceived stress and musculoskeletal pain in 15 and 16 year olds, to explore stress-pain associations and the probability that perceived stress (PSQ) was related to the reporting of pain and variations in pain, and to investigate possible differences in stress between different types of musculoskeletal pain in the adolescents. A cross-sectional study was conducted. Elementary schools participated. The outcomes were stress (Perceived stress questionnaire; PSQ) and musculoskeletal pain (pain/no pain, pain sites, pain duration and pain intensity (Visual analogue scale; VAS).

Results: Fifty-one point two percent $(N=422)$ reported pain, of which $70.8 \%$ reported long-term pain. Some more girls (57.9\%) reported pain. $22.0 \%$ of the study population reported moderate to severe stress (PSQ $\geq 0.45$ ), of which $79.6 \%$ were bothered by pain (Pearson Chi-square 38.47, $p \leq .001$ ). All stress and pain variables were significantly associated $(p<.01)$. The strongest association appeared between pain intensity (VAS) and stress (PSQ) $(r=0.40)$. Perceived stress (PSQ) was associated with the reporting of pain among the adolescents (Odds Ratio [OR] 1.68) and could explain some of the variation in pain intensity (VAS; $\beta=0.15, p<.001$ ) and number of pain sites $(\beta=0.14, p<.01)$, according to the regression analyses. There were no mean differences in stress (PSQ) between different types of musculoskeletal pain.

Conclusions: There was high prevalence of musculoskeletal pain, long-term pain and moderate to severe stress (PSQ $\geq 0.45$ ) in this study sample. Perceived stress (PSQ) was related to the reporting of musculoskeletal pain among the adolescents and could explain some of the variation in pain intensity (VAS) and number of pain sites. There were no differences in stress levels (PSQ) between different types of musculoskeletal pain in the adolescents.
\end{abstract}

Keywords: Adolescents, Perceived stress, Musculoskeletal pain, Stress-pain associations, Stress-related pain

\footnotetext{
* Correspondence: berit.osteras@hist.no

'Department of Physiotherapy, Faculty of Health Education and Social Work,

Sør-Trøndelag University College, Tungasletta 2, 7004 Trondheim, NORWAY

${ }^{2}$ Department of Psychology, Faculty of Social Sciences and Technology

Management, Norwegian University of Science and Technology (NTNU),

Trondheim, NORWAY
} 


\section{Background}

Several authors have characterized adolescence as a stressful, transiting stage of life [1-3], wherein pain experiences are common. [4-6] As pointed out by Ursin and Erikson [7] and Del Giudice et al. [1], stress is primarily positive and a normal activation response, leading to adaptation and change. However, the positive and functional role of stress might be diminished or entirely lost, when the stress response is detached from the stress stimuli, prolonged and sensitized $[1,8,9]$. This corresponds to the nature of pain. Pain is primarily positive (meaningful) and necessary for survival, but can lose its appropriate and positive function when it becomes long-term and sensitized [10]. Then, pain turns into a disabling and exhausting phenomena and might cause excessive stress and more pain $[10,11]$.

Population-based studies have found high prevalence of musculoskeletal pain in adolescents [12-15]. The young HUNT study 2008 reported chronic pain in $44.4 \%$ of the adolescents (aged 13-18) [6] and multisite pain in 8.8$31.0 \%$ [16]. In the young Swedish population there is an increase in neck and shoulder pain, which is described as a psychosocial stress-related phenomena [12, 13] Several authors have related neck, shoulder and back pain to stress and psychosocial factors, also in adolescents and children [3-5, 17-19]. In general, there appears to be an association between musculoskeletal pain and psychological factors in young people $[15,20]$.

There are several levels of stress-pain interactions, which can be termed neurophysiological, psychophysiological, cognitive-behavioral, and genetic-behavioral levels. The neurophysiological level explains how pain induces a stress response in the "supersystem", i.e., the interconnected nervous system, endocrine system and immune system [21-23]. The psychophysiological level includes the impact of emotions and negative stress on the supersystem and pain perception [21, 22]. The cognitive-behavioral level explains how appraisals of danger and coping capability (i.e., perceived stress) and choice of behavior (exposure, fear-avoidance; adaptive/ mal-adaptive) are transmitted by supersystem-activation and hence influence the pain experience [8, 21-23]. The genetic-behavioral level describes individual differences in the susceptibility of stress and pain due to differences in genotypes and epigenetic factors $[1,21,24,25]$.

A modified transactional model of stress explains how several factors contribute in the stress perception process on a cognitive-behavioral level, including personal aspects, stress exposures and reactions [26, 27]. Health consequences to stress depends on the individual appraisal of available resources under the influence of personality characteristics, according to this stress model [26, 27]. Earlier stressful life experiences seem to predict the current stress response and coping in adolescents, and can make young people vulnerable to actual life challenges and threaten their long-term health [28-30].

Negative stress and prolonged pain are health risks with adverse long-term health effects [11, 22]. Previous studies have demonstrated high prevalence of musculoskeletal pain and different psychosocial factors in adolescents $[6$, $13,15,20]$. There is however still lacking knowledge about the stress-pain relationship on a behavioral level in adolescents, which might illuminate possible mechanisms behind the development of illness among young people [31-35]. The main objectives of this work were to examine perceived stress and musculoskeletal pain in 16 year old adolescents with respect to 1) prevalence, 2) different stress-pain associations, 3) the probability that perceived stress (PSQ) was associated with the reporting of pain and variation in pain, and 4) possible differences in mean stress (PSQ) between different types of musculoskeletal pain.

\section{Method}

\section{Participants}

This study's cross-sectional sample included pupils in 10th grade (in their 16th or 17th year) in public elementary schools in the Trondheim municipality in Norway. Of a total of 17 schools, six agreed to participate. The schools varied in size and localization (from city to suburb), admitting pupils with different sociocultural- and economic backgrounds [36], and was representative of Norwegian 10th grade pupils. The data were collected during spring and autumn 2013.

\section{Procedure}

The data collection process was approved by the Regional Committee for Medical Research Ethics in Trondheim, and the study was in line with the Declaration of Helsinki [37]. The manuscript reporting adheres to STROBE guidelines for reporting observational Research (Additional file 1). The purpose of the study was explained in detail to the school principals and described in the invitation to participants and in the introduction of each questionnaire (Additional file 2), emphasizing the voluntary and anonymous participation. The respective principals from each of the schools approved the content of the questionnaire prior to agreeing to participate in the survey. Passive consent from the participants was found to be sufficient according to the Regional Committee for Medical Research Ethics, because no sensitive personally identifying data were collected. The pupils accepted the invitation to participate by answering the questionnaire. The pupils' answers were enclosed inside the questionnaire folder, thus invisible to the administrators (principals or teachers) who collected and returned the questionnaires in concealed envelopes. Questionnaire administration was completed in one session, in whole class groups, during one regular school period of $45 \mathrm{~min}$. 


\section{Study outcomes}

Perceived stress and musculoskeletal pain were outcome variables.

\section{Stress}

Stress was measured by the Perceived stress questionnaire (PSQ) $[26,38]$. PSQ is a valid instrument for measuring perceived stress [27, 39] in an adolescent population [40]. The PSQ includes 30 items that are assigned to four factors: worries, tension, (lack of) joy, and demands $[29,41]$. The responses to the items in the PSQ refers to experiences in the previous month, and each item is scored on a 4-point rating scale $(1=$ almost never, 2 =sometimes, $3=$ often and $4=$ usually). The resulting PSQ Total Score is linearly transformed between 0 and 1 according to Levenstein et al. [26]; PSQ $=($ raw value-30)/90. The cut-off score for moderate to severe stress was set to $\geq 0.45$ (higher stress). This was based on the mean stress score (total PSQ) in the present study population (0.33, standard deviation [SD] 0.16 ), which corresponds to previous studies using PSQ in population surveys [27, 41]. For the purpose of regression analyses, the PSQ-index was transformed to a 0-10 scale, termed the modified PSQ (mod.PSQ). Previous studies have shown a high Cronbach's $\alpha$ value of the PSQ $(\alpha=0.93)$ [27]. The authors of the PSQ granted us permission for translation and back translation of the PSQ, and authorized our final version.

\section{Pain}

Pain was measured by a dichotomous variable (bothered by pain/ not bothered by pain), questions about localization (pain site), duration, and intensity. Pain site was divided into six main categories, similar to the questionnaire in the Young-HUNT Study 2008 [16, 20]; head, neck, shoulder, back, arm, lower extremity, with an open line for additional sites. The six main pain sites were allocated into four groups for analytic purposes. Group one comprised head and eventually other pain sites. Group two comprised neck, shoulder and eventually other pain sites, excluding the head. Group three comprised back and eventually extremities (arm and/or lower extremity), but excluded head and neck and shoulder. Group four comprised extremity pain exclusively (arm and/ or lower extremity). Duration was divided into five categories; 0-2 weeks, 2-4 weeks, 1-2 months, $2-3$ months, 3 months or more, scored $1-5$. The latter pain duration category, i.e., 3 months or more was termed long-term pain, in accordance with the IASP Classification of Chronic Pain [42] regarding musculoskeletal pain. Intensity was measured by a Visual analogue scale (VAS: $0-10 \mathrm{~cm}$ ) [43] as the average pain during the last week, with 0 indicating "no pain" and 10 "worst pain imaginable". The VAS is reliable as a measure of pain intensity in children [44] and is used to detect differences in pain between groups of adolescents [45]. The pain questionnaire in this study also included two questions about injuries and/ or diseases which could possibly be related to the pain experience.

Demographic data included gender, height and weight. Height and weight were transformed into a body mass index (BMI) variable, which was included in the analyses. BMI is considered relevant for stress and pain, also in adolescents $[46,47]$.

\section{Statistical analysis}

All data are analyzed with IMB SPSS statistics 21. Cronbach's $\alpha$ was computed to estimate the internal consistency of the PSQ. Descriptive analyses including means and standard deviations for the continuous variables were calculated, separately for pain/ no pain. Person Chi-square was used in the $2 \times 2$-table of the dichotomous variables pain/ no pain and gender. Pearson product-moment correlation $(\mathrm{r})$ was used to test bivariate associations between the continuous variables. A bivariate logistic regression was performed to evaluate the probability that perceived stress (mod. PSQ) was associated with the reporting of pain among the adolescents, applying gender and BMI as covariates. Linear regression analyses evaluated the probability that pain duration, perceived stress (mod.PSQ), gender and BMI could explain variation in pain intensity (VAS) and number of pain sites, with the latter two variables applied as dependent variables. General Linear Models (GLM's) were used for between pain site group analyses, with adjustments for gender and BMI. Total stress (PSQ) and different factors of stress (worries, tension, joy, and demands) as well as pain duration and pain intensity (VAS) were applied as dependent variables, while gender and BMI were included as covariates. The adjustments for multiple comparisons were performed by using Bonferroni. To evaluate the strength of pain site group/ category on the dependent variables, effect sizes were calculated. Effect size (Cohen's d) is defined as the difference in outcome between the groups divided by the standard deviation of the baseline scores for this outcome [48]. Cohen [49] has presented some guidelines for the strength of effects: small (.20), medium (.50) and large $(.80+) . p$-values $\leq .05$ was considered statistically significant.

\section{Results}

430 questionnaires were distributed. The number of completed questionnaires returned was $N=423$, giving an overall response rate of $98.4 \%$; 218 (51.5\%) girls and 204 (48.2 \%) boys, and one participant did not report gender.

There was a small number of missing data. One participant did not report gender and one did not report on 
pain/ no pain. Two participants reported to have pain without specifying pain site. Mainly data from the items on page two in the questionnaire (the only back page) were exposed for missing. Apparently some of the participants overlooked these items, resulting in 18 missing responses on pain intensity (VAS), and 19 missing responses on pain duration. The participants with missing data were excluded listwise in the analyses.

Descriptive analyses are outlined in Tables 1 and 2. Study variables are displayed for the study sample $(N=422)$ in general, as well as separately for pain $(N=216) /$ no pain $(N=206)$. More than half of adolescents $(51.2 \%)$ reported to be bothered by musculoskeletal pain $(n=216)$, of which $70.8 \%(n=153)$ reported long-term pain. More girls (57.9 \%) than boys reported to be bothered by pain (Pearson Chi-square 7.11, $p \leq .05)$. The prevalence of moderate to severe stress (PSQ $\geq 0.45)$ was $22.0 \%(n=93)$. Most of the participants reporting moderate to severe stress (PSQ $\geq 0.45$ ) also were bothered by musculoskeletal pain ( $n=73$, Pearson Chi-square 38.47, $p \leq .001)$. The modified PSQ-index mean score in the study sample was 3.3. (SD 1.6). The group of participants with pain $(n=216$; "pain group") presented with higher mean scores for all stress variables than the group without pain, with highest mean scores for demands (4.9 [SD 2.2]) and tension (4.2 [SD 1.9]).

The most prevalent pain sites were lower extremity $(n=112)$, head $(n=76)$ and back pain $(n=69)$ (Table 2$)$. Mean (SD) pain intensity (VAS; $0-10)$ in the "pain group" was 4.5 (SD 2.4). Descriptive analyses of mean (SD) stress and pain variables in the four different pain site groups are presented in Table 3. The table shows highest stress and pain values in the head pain group
Table 2 Pain study variables

\begin{tabular}{ll}
\hline & $N=216$ \\
\hline Pain & $153(70.8 \%)$ \\
Long-term pain (3 months and more) & $76(35.2 \%)$ \\
Head pain & $40(18.5 \%)$ \\
Neck pain & $40(18.5 \%)$ \\
Shoulder pain & $69(31.9 \%)$ \\
Back pain & $22(10.2 \%)$ \\
Arm pain & $112(51.9 \%)$ \\
Lower extremity pain & $1.7(1.1)$ \\
Sites (0-6), mean (SD) & $3.3(1.3)$ \\
Duration (1-5), mean (SD) & $4.5(2.4)$ \\
Intensity (VAS; 0-10), mean (SD)
\end{tabular}

except for worries, which was slightly higher in the back pain group.

The PSQ showed a Cronbach's $\alpha$ of 0.90 . Correlation analyses of the continuous variables are presented in Table 4 , showing significant $(p<.01)$ correlations between all variables concerning stress and pain, as well as between BMI and pain intensity (VAS), and joy. The highest stress-pain correlations involved pain intensity (VAS); i.e., between VAS and total stress (PSQ) $(r=0.40)$ and between VAS and tension $(r=0.39)$. Pain intensity (VAS) also showed strong correlations to number of pain sites $(r=0.63)$ and pain duration $(r=0.69)$. BMI correlated weakly with joy and pain intensity (VAS) (Table 4).

All the regression analyses are summarized in Tables 5 and 6 . The logistic regression analyses revealed that perceived stress (mod. PSQ) was associated $(p<.001)$ with

Table 1 Study variables; prevalence separately for pain/ no pain

\begin{tabular}{|c|c|c|c|c|}
\hline & & Pain & No pain & Pearson \\
\hline & $N=422$ & $N=216$ & $N=206$ & Chi-square \\
\hline Girls & $218(51.7 \%)$ & $125(57.9 \%)$ & $92(44.6 \%)$ & \\
\hline Boys & $204(48.3 \%)$ & $91(42.1 \%)$ & $113(54.9 \%)$ & $7.11^{*}$ \\
\hline Pain & $216(51.2 \%)$ & & & \\
\hline Long-term pain ( 3 months and more) & $153(36.3 \%)$ & & & \\
\hline \multicolumn{5}{|l|}{ Stress } \\
\hline Higher stress (PSQ $\geq 0.45$ ) & $93(22.0 \%)$ & $74(34.3 \%)$ & $19(9.2 \%)$ & $38.47^{* *}$ \\
\hline Lower stress (PSQ < 0.45) & $329(78 \%)$ & $142(65.7 \%)$ & $187(90.8 \%)$ & \\
\hline Total (mod.PSQ; 0-10), mean (SD) & $3.3(1.6)$ & $3.9(1.7)$ & $2.7(1.3)$ & \\
\hline Worries (0-10), mean (SD) & $2.7(1.9)$ & $3.3(2.1)$ & $2.1(1.5)$ & \\
\hline Tension (0-10), mean (SD) & $3.5(1.8)$ & $4.2(1.9)$ & $2.8(1.3)$ & \\
\hline Joy $(0-10)$, mean $(S D)$ & $3.6(1.9)$ & $4.0(2.0)$ & $3.1(1.7)$ & \\
\hline Demands (0-10), mean (SD) & $4.2(2.1)$ & $4.9(2.2)$ & $3.5(1.8)$ & \\
\hline BMI & $20.8(3.1)$ & $21.0(3.1)$ & $20.5(3.2)$ & \\
\hline
\end{tabular}

PSQ Perceived stress questionnaire ${ }^{*} \mathrm{p} \leq .05 ;{ }^{*} \leq 001$ 
Table 3 Mean (SD) of primary outcome variables in the different pain site groups

\begin{tabular}{|c|c|c|c|c|c|c|c|}
\hline \multicolumn{8}{|l|}{ Pain site groups } \\
\hline & \multicolumn{5}{|l|}{ Stress } & \multicolumn{2}{|l|}{ Pain } \\
\hline & (mod.PSQ) & Worries & Tension & Joy & Demands & Duration & Intensity (VAS) \\
\hline Head $(n=76)$ & $4.24(1.84)$ & $3.55(2.22)$ & $4.53(1.88)$ & $4.43(1.65)$ & $5.36(2.42)$ & $3.37(1.37)$ & $4.77(2.43)$ \\
\hline Neck and shoulder $(n=36)$ & $3.73(1.73)$ & $3.11(1.99)$ & $4.29(2.04)$ & $3.91(2.23)$ & $4.52(1.84)$ & $3.25(1.14)$ & $4.27(2.25)$ \\
\hline $\operatorname{Back}(n=34)$ & $3.96(1.54)$ & $3.58(2.05)$ & $4.06(2.00)$ & $3.94(2.02)$ & $4.74(2.0)$ & $3.35(1.25)$ & $4.38(2.56)$ \\
\hline Extremities $(n=61)$ & $3.29(1.64)$ & $2.82(1.85)$ & $3.79(1.79)$ & $3.50(1.90)$ & $4.33(1.96)$ & $3.21(1.34)$ & $3.92(2.27)$ \\
\hline
\end{tabular}

mod.PSQ Modified Perceived stress questionnaire- index

the reporting of musculoskeletal pain among the adolescents, yielding an Odds Ratio (OR) of 1.68 (Tables 5 and 6). The full regression model explained between $14.4 \%$ (Cox \& Snell R Square) and $19.2 \%$ (Nagelkerke R Square) of the variance in the pain variable, correctly classifying $66.1 \%$ of the cases. The test for model fit yielded support for the full model with $X 2=56.34 \quad(p<.001)$ and a non-significant Hosmer and Lemeshow test $(p=0.875)$.

The linear regression analysis with pain intensity (VAS) as dependent variable, revealed that pain duration $(\beta=0.64$, $p<.001$ ) and perceived stress (PSQ, $\beta=0.15, p<.001$ ) explained some of the variation in pain intensity (VAS) (Tables 5 and 6). BMI demonstrated a weak explanatory effect $(\beta=0.09 p<.05)$. Gender did not explain any variation in pain intensity (VAS), according to the regression analyses. The regression model explained $52.3 \%$ of the variation in the pain intensity variable (VAS). The $\mathrm{R}^{2}(0.523)$ and significant $\mathrm{F}$-value $(93.31, p<.001)$ supported good fit of the model. The adjusted $\mathrm{R}^{2}(0.518)$ indicated very sparse loss of power. A Durbin-Watson test value close to two (1.70) indicated independence of the residuals. The linear regression analysis with pain sites as dependent variable, revealed that pain duration $(\beta=0.55, p<.001)$ and perceived stress (PSQ; $\beta=0.14, p<.01$ ) also explained some of the variation in the number of pain sites (Tables 5 and 6). Neither gender nor BMI seemed to explain variation in this pain variable. This regression model explained $37.7 \%$ of the variation in number of pain sites. The $\mathrm{R}^{2}(0.377)$ and significant $\mathrm{F}$-value $(51.67, p<.001)$ supported good fit of the model. The adjusted R2 (0.370) indicated limited loss of power. A Durbin-Watson test value close to two (1.97) indicated independence of the residuals.

Between pain site groups comparison analyses (Table 7) revealed no significant adjusted mean differences with respect to the included stress and pain variables (which are presented with the greatest differences in means in Table 3). Effect size calculations for the pairwise comparisons showed small to medium effects between head pain and extremity pain groups, and between back pain and extremity pain groups. The greatest effect size [0.5] appeared between head pain and extremity pain groups with respect to joy (Table 7).

Table $\mathbf{4}$ Correlations between the pain and stress study variables

\begin{tabular}{|c|c|c|c|c|c|c|c|c|c|}
\hline & \multirow{2}{*}{$\begin{array}{l}\text { Pain } \\
\text { sites }\end{array}$} & \multirow{2}{*}{$\begin{array}{l}\text { Pain } \\
\text { duration }\end{array}$} & Pain intensity & Total & \multirow[t]{2}{*}{ W } & \multirow[t]{2}{*}{$\mathrm{T}$} & \multirow[t]{2}{*}{ J } & \multirow[t]{2}{*}{ D } & \multirow[t]{2}{*}{$\mathrm{BMI}$} \\
\hline & & & VAS & PSQ & & & & & \\
\hline \multicolumn{10}{|l|}{ Pain } \\
\hline Sites & 1 & & & & & & & & \\
\hline Duration & $0.59^{* *}$ & 1 & & & & & & & \\
\hline Intensity (VAS) & $0.63^{* *}$ & $0.69^{* *}$ & 1 & & & & & & \\
\hline \multicolumn{10}{|l|}{ Stress } \\
\hline Total PSQ & $0.35^{* *}$ & $0.34^{* *}$ & $0.40^{* *}$ & 1 & & & & & \\
\hline Worries (W) & $0.29^{* *}$ & $0.28^{* *}$ & $0.34^{* *}$ & $0.94^{* *}$ & 1 & & & & \\
\hline Tension ( $\mathrm{T}$ ) & $0.37^{* *}$ & $0.36^{* *}$ & $0.39 * *$ & $0.84^{* *}$ & $0.70^{* *}$ & 1 & & & \\
\hline Joy $(J)$ & $0.22^{* *}$ & $0.25^{* *}$ & $0.30^{* *}$ & $0.67^{* *}$ & $0.53^{* *}$ & $0.50^{* *}$ & 1 & & \\
\hline Demands (D) & $0.30^{* *}$ & $0.25^{* *}$ & $0.31^{* *}$ & $0.79^{* *}$ & $0.69^{* *}$ & $0.61^{* *}$ & $.37^{* *}$ & 1 & \\
\hline BMI & 0.19 & 0.49 & $0.12^{*}$ & 0.02 & 0.04 & 0.01 & $0.12^{*}$ & -0.05 & 1 \\
\hline Cronbach's a & & & & 0.90 & & & & & \\
\hline
\end{tabular}


Table 5 Summary of the regression analyses

Results of logistic regression analyses evaluating the probability that perceived stress was associated with the reporting of pain (the dependent dichotomous variable pain/no pain)

\begin{tabular}{lllll}
\hline & B & \multicolumn{2}{c}{$95 \%$ Cl for Odds Ratio } \\
\cline { 3 - 5 } & & Lower & Odds & Upper \\
\hline Constant & -2.51 & & & \\
Stress (mod.PSQ; 0-10) & $0.52^{* * *}$ & 1.42 & 1.68 & 1.99 \\
\hline Control variables: gender and BMI ${ }^{* * *} p<.001$
\end{tabular}

Control variables: gender and $\mathrm{BMI}{ }^{* * *} p<.001$

The responses concerning injuries and/ or diseases possibly related to the pain experience were very divergent and difficult to categorize for analytic purposes. To avoid group level bias due to individual interpretations, these items were excluded in the subsequent analysis.

\section{Discussion}

The objectives in this study were to examine perceived stress in relation to musculoskeletal pain in adolescents; the prevalence, associations, stress as a possible explanatory factor of pain and variation in pain, and possible differences in mean stress (PSQ, worries, tension, joy, demands) between different types of musculoskeletal pain.

The findings demonstrated a high prevalence of musculoskeletal pain $(51.2 \%)$ and long-term musculoskeletal pain (36.3\%) in the adolescents. This supports findings from the Young-HUNT Study 2008 [6] and confirms that musculoskeletal pain is common and normal to experience during adolescence [50]. Lower extremity pain was the pain site most frequently reported, followed by head and back pain (Table 2). The prevalent lower extremity and back pain in adolescents corresponds with the findings by Rathleff et al. [14]. Lower extremity pain

Table 6 Summary of the regression analyses

Results of the linear regression analysis evaluating the probability that perceived stress could explain variation in pain intensity (VAS)

$\begin{array}{llllll} & \text { B } & \text { SE B } & \beta & F & R^{2} \\ \text { Constant } & -2.78 & 0.74 & & & \\ \text { Pain duration (1-5) } & 1.21 & 0.08 & 0.64^{* * *} & & \\ \text { Stress (mod.PSQ; 0-10) } & 0.25 & 0.07 & 0.15^{* * *} & & \\ \text { Gender } & -0.19 & 0.22 & -0.03 & & \\ \text { BMl } & 0.07 & 0.03 & 0.09^{*} & 93.31^{* * *} & 0.52\end{array}$

Results of the linear regression analysis evaluating the probability that perceived stress could explain variation in number of pain sites

\begin{tabular}{llllll} 
Constant & 0.68 & 0.35 & & & \\
Pain duration (1-5) & 0.43 & 0.04 & $0.55^{* * *}$ & & \\
Stress (mod.PSQ; 0-10) & 0.10 & 0.03 & $0.14^{* *}$ & & \\
Gender & 0.01 & 0.11 & 0.0 & & \\
BMI & 0.01 & 0.02 & 0.03 & $51.67^{* * *}$ & 0.37 \\
\hline
\end{tabular}

CI Confidence interval, VAS Visual analogue scale, mod.PSQ Modified Perceived stress questionnaire-index

${ }^{*} p<.05 ;{ }^{* *} p<.01 ;{ }^{* * *} p<.001$ in children and adolescents has generally been related to growth and growth in combination with vigorous exercise [51]. Back pain has additionally often been related to habitual posture, lack of physical activity and variation in body movement $[5,52]$. Head pain or headache however, has more commonly been associated to perceived stress and psychological conditions, also in children and adolescents $[4,17,53]$. The "head pain group" of this study also presents with the highest mean score of total stress (PSQ) (Table 3).

The mean stress level (PSQ-index mean score; 0.33 [SD 0.16]) of the study sample corresponds to previous studies in young people when applying the same stress instrument $[39,40]$, and the cut-off score for moderate to higher stress levels was set according to this. By using Bergdahl and Bergdahl [54] found a prevalence of high stress at $4.0 \%$ in their Swedish the PSQ $>0.46$ cut-off score, population based study (1275 subjects; 581 men and 694 women, aged $30+$ ). In contrast, the prevalence of higher stress (PSQ $\geq 0.45)$ among the adolescents in this study was $22.0 \%$. In a general German population (2483 subjects; 1206 men and 1346 women, aged 18+), the prevalence of moderate to severe stress ( $P S Q \geq 45$ ) was $17.6 \%$ [41]. Thus, the adolescents in this study had a greater prevalence of moderate to severe stress (PSQ $\geq 45$ ) than what is previously found in other populations. The highest score among the adolescents was for demands (Table 1). This might indicate that coping with demands is a main stressor during adolescence, which is also discussed in Wiklund et al. [4]. Wiklund et al. [4] found that perceived stress in the form of pressure and demands were strongly correlated with health complaints and anxiety in Swedish older adolescents (16-18 years old). By more life experience, total stress perception seems to decrease [54].

The findings revealed significant associations between all factors of stress and pain measured in this study (Table 4). Higher levels of stress, including worries, tension, lack of joy and demands, correlated with more pain sites, longer pain duration and higher pain intensity (VAS). This might support the works of Murberg and Bru [17] and Eckhoff and Kvernmo [15], focusing on school-related stress. Looking at possible school-related stressors in a sample of 531 pupils aged 13-16 years, Murberg and Bru [18] found an association between these given stressors and psychosomatic symptoms. Eckhoff and Kvernmo [15] presented similar findings in a recent study based on The Norwegian Arctic Adolescent Health Study. They found school-related stress to be among the most important factors associated with musculoskeletal pain, and that musculoskeletal pain sites were associated with psychosocial problems.

The stress-pain association demonstrated in this study supports theories and basic research regarding 
Table 7 Adjusted mean $(95 \%$ Cl) difference between pain site groups with corresponding effect size

\begin{tabular}{|c|c|c|c|c|c|}
\hline \multicolumn{2}{|l|}{ Pain site groups } & \multicolumn{4}{|c|}{ Adjusted mean difference between groups ${ }^{\mathrm{a}}$ (95\% Cl) [effect size] } \\
\hline & & Tension & Joy & Demands & Pain intensity (VAS) \\
\hline \multirow[t]{3}{*}{ Head } & Neck and shoulder & $0.20(-0.80-1.19)[0.1]$ & $0.64(-0.48-1.74)[0.3]$ & $0.68(-0.52-1.88)[0.3]$ & $0.40(-0.79-1.60)[0.2]$ \\
\hline & Back & $-0.05(-1.1-1.0)[-0.0]$ & $0.60(-0.58-1.78)[0.3]$ & $0.13(-1.15-1.41)[0.1]$ & $0.09(-1.18-1.35)[0.0]$ \\
\hline & Extremities & $0.60(-0.29-1.48)[0.3]$ & $0.87(-0.12-1.86)[0.5]$ & $0.86(-0.22-1.93)[0.4]$ & $0.71(-0.35-1.77)[0.3]$ \\
\hline \multirow[t]{2}{*}{ Neck, shoulder } & Back & $-0.25(-1.42-0.91)[-0.1]$ & $-0.03(-1.34-1.27)[-0.0]$ & $-0.55(-1.97-0.86)[-0.3]$ & $-0.32(-1.73-1.09)[-0.1]$ \\
\hline & Extremities & $0.40(-0.63-1.43)[0.2]$ & $0.23(-0.92-1.39)[0.1]$ & $0.17(-1.07-1.43)[0.1]$ & $0.31(-0.94-1.55)[0.1]$ \\
\hline Back & Extremities & $0.65(-0.42-1.73)[0.4]$ & $0.27(-0.94-1.47)[0.1]$ & $0.73(-0.58-2.04)[0.4]$ & $0.63(-0.67-1.92)[0.3]$ \\
\hline
\end{tabular}

No statistical significant mean differences between groups

$\mathrm{Cl}$ Confidence interval

${ }^{\text {a } T h e ~ m e a n ~ d i f f e r e n c e s ~ b e t w e e n ~ g r o u p s ~ w e r e ~ a d j u s t e d ~ f o r ~ g e n d e r ~ a n d ~ B M I ~}$

the interconnection between these phenomena [11, 23, $24,55]$. The highest stress-pain correlation in the study appeared between stress (total PSQ and tension) and pain intensity (measured by VAS) (Table 4). With respect to previous studies using PSQ as a measure of stress, Kocalevent et al. [41] demonstrated significant correlations between stress and fatigue in a general German population. Mechanisms behind symptoms in fatigue and long-term pain conditions have been proved to be similar [56].

The results of the regression analyses imply that perceived stress (PSQ) was related to the reporting of musculoskeletal pain among the adolescents and probably explained some of the variation in pain intensity (VAS) and number of pain sites, controlled for gender and BMI (Tables 5 and 6). Naturally, the pain duration variable explained even more of the variation in pain intensity (VAS) and number of pain sites. When pain becomes persistent, sensitization mechanisms might be induced, resulting in a vicious circle where pain produces pain $[9,11,56,57]$. However, the regression models do not explain all the variation in the dependent pain variables. The variation in pain might also be explained by other factors, e.g., genetic and social factors [21-24], physical/ sports activities, and injuries and diseases [14, 51, 52]. Studies based on the Young-HUNT study 2008 found that both chronic pain and psychological symptoms "runs in the family", i.e., are most prevalent among adolescents with parents suffering from similar symptoms. [58, 59] Several authors have confirmed higher prevalence of musculoskeletal pain among girls [14, 16, 20,60], suggesting gender to be an explanatory factor of pain. There was some higher prevalence of musculoskeletal pain among the girls also in this study sample (Table 1). However, girls also seem to be more prone to perceived stress [2, 4], suggesting stress to be a possible mediating factor of pain across genders. However, this was beyond the scope of this study.

The correlation between pain intensity (VAS) and tension can also be interpreted in the view of the modified transactional model of stress [26, 27]. The different factors of stress in this model correspond to the factors of stress in the PSQ, where tension represent the stress reaction. As the stress reaction has the potential to modulate or inhibit pain through the cortisol awakening response, the associated high pain intensity might indicate a deficiency in these mechanisms. The stress response might reflect a sustained and catabolic state of arousal [7], a chronic stress response possibly involving cortisol dysfunction $[11,28]$. The stress response appears to no longer have a pain modulating/inhibiting function. Together with the association between pain intensity (VAS), pain duration, and pain sites (Table 3), this might imply that stress-induced pain sensitization [57] is present among the adolescents.

There were no significant mean differences between groups of adolescents with various types of musculoskeletal pain (Table 3 and 7). For instance, the neck/shoulder pain group presented with equivalent levels of stress as the extremity pain group. This contradicts the traditional view, considering neck and shoulder pain as more stress-related than extremity pain [3, 4, 13, 17]. This assumption resulted in an increased focus on cognitivebehavioral treatments for the presumed stress-related musculoskeletal pain conditions, showing a lack of success $[61,62]$. The findings in this study underscores the importance of a comprehensive understanding of pain mechanisms in young people, as well as more appropriate and effective treatment and prevention approaches for this group. The group with head pain presented with the highest mean values of stress and pain variables in this study, though not significantly different (Table 3 and 7). Pairwise comparisons between pain groups including head or back pain, and the group of extremity pain exclusively, revealed small to medium effects sizes. The largest effect (0.5) appeared for (lack of) joy, comparing head and extremity pain. This might indicate that head pain affect happiness to some higher degree than extremity pain. In adolescents, head pain is often associated with other conditions such as anxiety and mood disorders [63] [64]. 


\section{Clinical implications}

This study suggests that perceived stress (measured by the PSQ) can explain some of the probability of pain and variation in pain intensity and number of pain sites in adolescents (Tables 5 and 6). The findings shed some light on plausible mechanisms behind pain and illness in young people. Increased knowledge about this is crucial in order to succeed in treatment and health promotion among young people [38]. The demonstrated corresponding levels of stress (PSQ) between different types of musculoskeletal pain might also be clinical interesting. The lack of correlation between levels of stress and different types of musculoskeletal pain challenges common clinical understanding in that a painful knee could be considered just as affected by stress-mechanisms as neck and shoulder pain (Table 7). The association between pain intensity (VAS) and tension (stress-reaction) (Table 4), implies possible stress-induced sensitization among adolescents. If we increase stress and/or pain by our clinical methods and approaches, e.g., by intrusive techniques or highly demanding exercises, it might worsen and prolong pain- and stress-sensitized conditions and lead to more illness among the young people $[11,56]$.

\section{Strengths and limitations}

The study investigated critical health parameters in adolescents, i.e., perceived stress and pain, which previously has been lacking $[36,38]$. The findings shed new light on stress-pain associations in young people and provide a basis for further research. The applied stress instrument (PSQ) has several advantages, identifying direct effects of resources on the stress perception and indirect effects on health-related aspects [26, 27]. PSQ contains both positively and negatively formulated items in order to reduce acquiescent bias [44]. Similar to all questionnairebased surveys, this study might be subject to potential selfreporting bias. Applying a relatively large sample size and powerful methods, these possible bias effects might be diminished. The items concerning pain-related injuries/ diseases were excluded for analyses, due to apparently very inconsistent comprehension of these concepts among the participants. In future studies this items can be specified, e.g., by defining alternative diagnosis/ conditions to choose between. However modern pain science focuses less on locale pain structures and local causes, especially in longterm pain conditions $[11,35,55,56]$. The mechanisms behind the persistent and exhausting pain, on a "supersystem"-level, is considered more relevant and important [11, 22, 23]. Nevertheless, the cross-sectional design does not allow us to determine causal direction among the variables. The associations between stress and pain do not reveal whether the adolescents are stressed because of pain, or have pain because of stress. Further studies are needed to compliment the findings from this study, including more focus on protective health resources and gender differences among adolescents.

\section{Conclusion}

Perceived stress and musculoskeletal pain are significantly associated in adolescents, according to the findings in this study. Different aspects of pain, i.e., number of pain sites, pain duration and pain intensity were significantly correlated with stress measured by different factors, i.e., worries, tension, joy and demands. Perceived stress (PSQ) was related to the reporting of musculoskeletal pain among the adolescents and could explain some of the variation in pain intensity (VAS) and number of pain sites. There were no significant differences in stress between various types of musculoskeletal pain, suggesting that stress-mechanisms are relevant in diverse musculoskeletal pain conditions in young people.

\section{Additional files}

Additional file 1: STROBE checklist. (80.0 KB)

Additional file 2: Invitasjon til deltagelse i spørreundersøkelse for 10. trinn i Trondheim kommune. (23.2 KB)

\section{Abbreviations}

PSQ: Perceived stress questionnaire; Mod.PSQ: Modified Perceived stress questionnaire-index.; VAS: Visual analogue scale; SD: Standard deviation; Cl: Confidence interval; IASP: International Association for the Study of Pain; BMI: Body mass index; GLM: General linear model; OR: Odds Ratio; W: Worries; T: Tension; J: Joy; D: Demands.

\section{Competing Interests}

The authors declare that they have no competing interests.

\section{Authors' contributions}

$\mathrm{B} \varnothing$ has made substantial contributions to conception and design, to acquisition and analysis and interpretation of data, and to drafting and revising the manuscript. HS participated in design and in revision of the manuscript for important intellectual content. $\mathrm{MH}$ participated in design and in coordination of the writing process, in the sequence alignment, and in revising the manuscript critically. All authors read and approved the final manuscript.

\section{Acknowledgements}

Many thanks to the pupils who accepted our invitation to participate in the study and carefully answered the questionnaire. Thanks to the principals of the participating elementary schools in Trondheim, who accepted and appreciated the invitation to be included in the study. Also many thanks to the teachers, who administrated the questionnaires.

This study was funded by a PhD grant from Sør-Trøndelag University College.

The data collection process was approved by the Regional Committee for Medical

Research Ethics, and the study was in line with the Declaration of Helsinki.

Received: 1 July 2015 Accepted: 12 October 2015

Published online: 23 October 2015

\section{References}

1. Del Giudice M, Ellis BJ, Shirtcliff EA. The adaptive calibration model of stress responsivity. Neurosci Biobehav Rev. 2011;35(7):1562-92. doi:10.1016/ j.neubiorev.2010.11.007. Epub 2010 Dec 8. 
2. Moksnes UK, Espnes GA, Haugan G. Stress, sense of coherence and emotional symptoms in adolescents. Psychol Health. 2013;29(1):32-49. doi:10.1080/08870446.2013.822868. Epub 2013 Aug 1.

3. Diepenmaat AC, van der Wal MF, de Vet HC, Hirasing RA. Neck/shoulder, low back, and arm pain in relation to computer use, physical activity, stress, and depression among Dutch adolescents. Pediatrics. 2006;117(2):412-6.

4. Wiklund $M$, Malmgren-Olsson EB, Ohman A, Bergström E, Fjellman-Wiklund A. Subjective health complaints in older adolescents are related to perceived stress, anxiety and gender - a cross-sectional school study in Northern Sweden. BMC Public Health. 2012;12:993. doi:10.1186/1471-2458-12-993.

5. Prins $Y$, Crous L, Louw QA. A systematic review of posture and psychosocial factors as contributors to upper quadrant musculoskeletal pain in children and adolescents. Physiother Theory Pract. 2008;24(4):221-42. doi:10.1080/ 09593980701704089

6. Hoftun GB, Romundstad PR, Zwart JA, Rygg M. Chronic idiopathic pain in adolescence-high prevalence and disability: the young HUNT Study 2008. Pain. 2011;152(10):2259-66. doi:10.1016/j.pain.2011.05.007. Epub 2011 Jun 16.

7. Ursin H, Eriksen HR. The cognitive activation theory of stress. Psychoneuroendocrinology. 2004;29(5):567-92.

8. Eriksen HR, Ursin H. Subjective health complaints, sensitization, and sustained cognitive activation (stress). J Psychosom Res. 2004;56(4):445-8.

9. Ursin H, Eriksen HR. Cognitive activation theory of stress (CATS). Neurosci Biobehav Rev. 2010;34(6):877-81. doi:10.1016/j.neubiorev.2009.03.001. Epub 2009 Mar 10.

10. Brodal P. Sentralnervesystemet [the central nervous system]. 5th ed. Oslo: Universitetsforlaget; 2013. p. 230-1.

11. Hannibal KE, Bishop MD. Chronic stress, cortisol dysfunction, and pain: a psychoneuroendocrine rationale for stress management in pain rehabilitation. Phys Ther. 2014;94(12):1816-25. doi:10.2522/ptj.20130597. Epub 2014 Jul 17.

12. Danielsson M, Heimerson I, Lundberg U, Perski A, Stefansson CG, Akerstedt T. Psychosocial stress and health problems: Health in Sweden: The National Public Health Report 2012. Scand J Public Health. 2012;40(9 Suppl):121-34. doi:10.1177/1403494812459469.

13. Lager A, Berlin M, Heimerson I, Danielsson M. Young people's health: health in Sweden: the national public health report 2012. Scand J Public Health. 2012;40(9 Suppl):42-71. doi:10.1177/1403494812459459.

14. Rathleff MS, Roos EM, Olesen JL, Rasmussen S. High prevalence of daily and multi-site pain —a cross-sectional population-based study among 3000 Danish adolescents. BMC Pediatr. 2013;13:191. doi:10.1186/1471-2431-13-191.

15. Eckhoff $C$, Kvernmo S. Musculoskeletal pain in Arctic indigenous and nonindigenous adolescents, prevalence and associations with psychosocial factors: a population-based study. BMC Public Health. 2014;18(14):617. doi:10.1186/1471-2458-14-617.

16. Skrove M, Romundstad P, Indredavik MS. Chronic multisite pain in adolescent girls and boys with emotional and behavioral problems: the Young-HUNT study. Eur Child Adolesc Psychiatry. 2014. doi:10.1007/s00787014-0601-4.

17. Murberg TA, Bru E. School-related stress and psychosomatic symptoms among Norwegian adolescents. Sch Psychol Int. 2004;25(3):317-32. doi:10.1177/0143034304046904

18. Christensen J, Fisker A, Mortensen EL, Olsen LR, Mortensen OS, Hartvigsen J, et al. Comparison of mental distress in patients with low back pain and a population-based control group measured by symptoms check list - a case-referent study. Scand J Public Health. 2015. doi:10.1177/1403494815581697.

19. Mikkonen P, Heikkala E, Paananen M, Remes J, Taimela S, Auvinen J, Karppinen J. Accumulation of psychosocial and lifestyle factors and risk of low back pain in adolescence: a cohort study. Eur Spine J. 2015 Jun 13. [Epub ahead of print]

20. Hoftun GB, Romundstad PR, Rygg M. Factors associated with adolescent chronic non-specific pain, chronic multisite pain, and chronic pain with high disability: the young-HUNT study 2008. J Pain. 2012;13(9):874-83. doi:10.1016/j.jpain.2012.06.001. Epub 2012 Jul 24.

21. Lovallo WR. Stress \& health. Biological and psychological interactions. Thousand Oaks: Sage Publications; 2005. p. 123-94.

22. Chapman CR, Tuckett RP, Song CW. Pain and stress in a systems perspective: reciprocal neural, endocrine, and immune interactions. J Pain. 2008;9(2):122-45. Epub 2007 Dec 21. Review.

23. Irwin MR, Cole SW. Reciprocal regulation of the neural and innate immune systems. Nat Rev Immunol. 2011;11(9):625-32. doi:10.1038/nri3042.
24. Sterrenburg L, Gaszner B, Boerrigter J, Santbergen L, Bramini M, Elliott E, et al. Chronic stress induces sex-specific alterations in methylation and expression of corticotropin-releasing factor gene in the rat. PLoS One. 2011;6(11), e28128. doi:10.1371/journal.pone.0028128. Epub 2011 Nov 23.

25. Sterrenburg L, Gaszner B, Boerrigter J, Santbergen L, Bramini M, Roubos EW, et al. Kozicz T Sex-dependent and differential responses to acute restraint stress of corticotropin-releasing factor-producing neurons in the rat paraventricular nucleus, central amygdala, and bed nucleus of the stria terminalis. J Neurosci Res. 2012;90(1):179-92. doi:10.1002/jnr.22737. Epub 2011 Sep 15.

26. Levenstein S, Prantera C, Varvo V, Scribano ML, Berto E, Luzi C, et al. Development of the perceived stress questionnaire: a new tool for psychosomatic research. J Psychosom Res. 1993;37(1):19-32.

27. Kocalevent RD, Levenstein S, Fliege H, Schmid G, Hinz A, Brähler E, et al. Contribution to the construct validity of the perceived stress questionnaire from a population-based survey. J Psychosom Res. 2007;63(1):71-81.

28. Hagan MJ, Roubinov DS, Gress-Smith J, Luecken LJ, Sandler IN, Wolchik S. Positive parenting during childhood moderates the impact of recent negative events on cortisol activity in parentally bereaved youth. Psychopharmacology (Berl). 2011;214(1):231-8. doi:10.1007/s00213-010-18895. Epub 2010 Jun 3.

29. Dietz LJ, Stoyak S, Melhem N, Porta G, Matthews KA, Walker Payne M, et al. Cortisol response to social stress in parentally bereaved youth. Biol Psychiatry. 2013;73(4):379-87. doi:10.1016/j.biopsych.2012.08.016.

30. Bridget M, Kuehn MSJ. AAP: toxic stress threatens Kids' long-term health. JAMA. 2014;312(6):585-6.

31. Jones GT. Pain in children-a call for more longitudinal research. Pain. 2011:152(10):2202-3. doi:10.1016/j.pain.2011.06.016. Epub 2011 Jul 5.

32. Dean $E$, Söderlund $A$. What is the role of lifestyle behaviour change associated with non-communicable disease risk in managing musculoskeletal health conditions with special reference to chronic pain? BMC Musculoskelet Disord. 2015;16:87. doi:10.1186/s12891-015-0545-y.

33. Norwegian Institute of Public Health. Health in children and young people - The Public Health Report 2014. http://www.fhi.no/artikler/?id=111677. Published 07.10.2014, updated 09.04.2015. Accessed 10 Sept 2015.

34. Norwegian Institute of Public Health. Norwegian priorities in global health http://www.fhi.no/artikler/?id=103215, published 04.02.2013, updated 07.05.2015. Accessed 10 Sept 2015.

35. De Vriendt T, Clays E, Maes L, De Bourdeaudhuij I, Vicente-Rodriquez G, Moreno LA, et al. European adolescents' level of perceived stress and its relationship with body adiposity-the HELENA Study. Eur J Public Health. 2012;22(4):519-24. Epub 2011 Sep 10.

36. Trondheim commune, ownership unit. «Living conditions 2011. A rapport on living conditions in Trondheim», March 2012. http:// www.trondheim.kommune.no. Accessed 20 Jan 2013.

37. The World Medical Association (WMA). Declaration of Helsinki - ethical principles for medical research involving human subjects. Fortaleza: 64th WMA General Assembly; 2013. http://www.wma.net/en/30publications/ 10policies/b3/index.html.

38. Fliege $H$, Rose $M$, Arck P, Walter OB, Kocalevent RD, Weber $C$, et al. The Perceived Stress Questionnaire (PSQ) reconsidered: validation and reference values from different clinical and healthy adult samples. Psychosom Med. 2005;67(1):78-88.

39. Montero-Marin J, Piva Demarzo MM, Pereira JP, Olea M, García-Campayo J. Reassessment of the psychometric characteristics and factor structure of the Perceived Stress Questionnaire (PSO): analysis in a sample of dental students. PLoS One. 2014;9(1):e87071. doi:10.1371/journal.pone.0087071.

40. Stinson JN, McGrath PJ, Hodnett ED, Feldman BM, Duffy CM, Huber AM, et al. An internet-based self-management program with telephone support for adolescents with arthritis: a pilot randomized controlled trial. J Rheumatol. 2010;37(9):1944-52. doi:10.3899/jrheum.091327. Epub 2010 Jul 1.

41. Kocalevent RD, Hinz A, Brähler E, Klapp BF. Determinants of fatigue and stress. BMC Res Notes. 2011;20(4):238. doi:10.1186/1756-0500-4-238.

42. The International Association for the Study of Pain [IASP] 2014. Classification of Chronic Pain, Second Edition (Revised). August 06, 2014. http://www.iasppain.org/PublicationsNews. Accessed 20 Jan 2015.

43. Price DD, McGrath PA, Rafii A, Buckingham B. The validation of visual analogue scales as ratio scale measures for chronic and experimental pain. Pain. 1983;17(1):45-56

44. Bailey B, Gravel J, Daoust R. Reliability of the visual analog scale in children with acute pain in the emergency department. Pain. 2012;153(4):839-42. doi:10.1016/j.pain.2012.01.006. Epub 2012 Feb 4. 
45. Sugiura S, Aoki Y, Toyooka T, Shiga T, Otsuki K, Aikawa E, et al. Characteristics of low back pain in adolescent patients with early-stage spondylolysis evaluated using a detailed visual analogue scale. Spine (Phila Pa 1976). 2015;40(1):E29-34. doi:10.1097/BRS.0000000000000657.

46. Sethi J, Sandhu JS, Imbanathan V. Effect of Body Mass Index on work related musculoskeletal discomfort and occupational stress of computer workers in a developed ergonomic setup. Sports Med Arthrosc Rehabil Ther Technol. 2011:3(1):22. doi:10.1186/1758-2555-3-22.

47. Silva MR, Badaró AF, Dall'Agnol MM. Low back pain in adolescent and associated factors: a cross sectional study with schoolchildren. Braz J Phys Ther. 2014;18(5):402-9. Epub 2014 Oct 10.

48. Hartung J, Knapp G, Sinha BK. Statistical meta-analysis with application. New York: Wiley; 2008.

49. Cohen J. Statistical power analysis for the behavioral sciences. 2nd ed. Hillsdale: Lawrence Earlbaum Associates; 1988.

50. Perquin CW, Hazebroek-Kampschreur AA, Hunfeld JA, Bohnen AM, van Suijlekom-Smit LW, Passchier J, et al. Pain in children and adolescents: a common experience. Pain. 2000;87(1):51-8.

51. El-Metwally A, Salminen JJ, Auvinen A, Kautiainen H, Mikkelsson M. Risk factors for traumatic and non-traumatic lower limb pain among preadolescents: a population-based study of Finnish schoolchildren. BMC Musculoskelet Disord. 2006;18(7).

52. Boćkowski L, Sobaniec W, Kułak W, Smigielska-Kuzia J, Sendrowski K, Roszkowska M. Low back pain in school-age children: risk factors, clinical features and diagnostic managment. Adv Med Sci. 2007:52 Suppl 1:221-3.

53. Galli F, Caputi M, Gallucci M, Termine C, Chiappedi M, Balottin U. Headache and psychological disorders in children and adolescents: a crossgenerational study. Minerva Pediatr. 2015 Jun 4. [Epub ahead of print]

54. Bergdahl J, Bergdahl M. Perceived stress in adults: prevalence and association of depression, anxiety and medication in a Swedish population. Stress Health. 2002;18:235-41. doi:10.1002/smi.946. www.interscience.wiley.com.

55. Linton SJ, Shaw WS. Impact of psychological factors in the experience of pain. Phys Ther. 2011;91(5):700-11. doi:10.2522/ptj.20100330. Epub 2011 Mar 30.

56. Meeus M, Nijs J, Hermans L, Goubert D, Calders P. The role of mitochondrial dysfunctions due to oxidative and nitrosative stress in the chronic pain or chronic fatigue syndromes and fibromyalgia patients: peripheral and central mechanisms as therapeutic targets? Expert Opin Ther Targets. 2013;17(9):1081-9. doi:10.1517/14728222.2013.818657. Epub 2013 Jul 9.

57. Moeller-Bertram T, Strigo IA, Simmons AN, Schilling JM, Patel P, Baker DG. Evidence for acute central sensitization to prolonged experimental pain in posttraumatic stress disorder. Pain Med. 2014;15(5):762-71. doi:10.1111/ pme.12424. Epub 2014 Apr 16.

58. Kaasbøll J, Lydersen S, Indredavik MS. Psychological symptoms in children of parents with chronic pain-the HUNT study. Pain. 2012;153(5):1054-62. doi:10.1016/j.pain.2012.02.013. Epub 2012 Mar 21.

59. Hoftun GB, Romundstad PR, Rygg M. Association of parental chronic pain with chronic pain in the adolescent and young adult: family linkage data from the HUNT Study. JAMA Pediatr. 2013;167(1):61-9. doi:10.1001/ jamapediatrics.2013.422.

60. Norwegian Social Research (NOVA). "Ungdata". National results 2014. NOVA Report 7/15. ISBN: 978-82-7894-556-8 (print), 978-82-7894-557-5 (electronical). http://www.hioa.no/Om-HiOA/Senter-for-velferds-ogarbeidslivsforskning/NOVA. Accessed 20 Sept 2015.

61. Monticone M, Cedraschi C, Ambrosini E, Rocca B, Fiorentini R, Restelli M, et al. Cognitive-behavioural treatment for subacute and chronic neck pain. Cochrane Database Syst Rev. 2015;5, CD010664. doi:10.1002/ 14651858.CD010664.pub2.

62. Pincus T, Anwar S, McCracken LM, McGregor A, Graham L, Collinson M, et al. Delivering an Optimised Behavioural Intervention (OBI) to people with low back pain with high psychological risk; results and lessons learnt from a feasibility randomised controlled trial of Contextual Cognitive Behavioural Therapy (CCBT) vs Physiotherapy. BMC Musculoskelet Disord. 2015;16(1):147. doi:10.1186/s12891-015-0594-2.

63. Bruffaerts R, Demyttenaere K, Kessler RC, Tachimori H, Bunting B, Hu C, et al. The associations between preexisting mental disorders and subsequent onset of chronic headaches: a worldwide epidemiologic perspective. J Pain. 2015;16(1):42-52. doi:10.1016/j.jpain.2014.10.002. Epub 2014 Oct 22.

64. Galli F, Caputi M, Gallucci M, Termine C, Chiappedi M, Balottin U. Headache and psychological disorders in children and adolescents: a crossgenerational study. Minerva Pediatr. 2015. [Epub ahead of print]

\section{Submit your next manuscript to BioMed Central and take full advantage of:}

- Convenient online submission

- Thorough peer review

- No space constraints or color figure charges

- Immediate publication on acceptance

- Inclusion in PubMed, CAS, Scopus and Google Scholar

- Research which is freely available for redistribution

Submit your manuscript at www.biomedcentral.com/submit 